\title{
Ejection Time-Corrected Systolic Velocity Improves Accuracy in the Evaluation of Myocardial Dysfunction: A Study in Piglets
}

\author{
Hans Henrik Odland • Grete Anette Birkeland Kro • \\ Berit H. Munkeby • Thor Edvardsen • \\ Ola Didrik Saugstad • Erik Thaulow
}

Received: 2 May 2010/ Accepted: 26 July 2010/Published online: 19 August 2010

(c) The Author(s) 2010. This article is published with open access at Springerlink.com

\begin{abstract}
This study aimed to assess the effect of correcting for the impact of heart rate (HR) or ejection time (ET) on myocardial velocities in the long axis in piglets undergoing hypoxia. The ability to eject a higher volume at a fixed ET is a characteristic of contractility in the heart. Systolic velocity of the atrioventricular annulus displacement is directly related to volume changes of the ventricle. Both ET and systolic velocity may be measured in a single heartbeat. In 29 neonatal pigs, systolic velocity and ET were measured with tissue Doppler techniques in the mitral valve annulus, the tricuspid valve annulus, and the septum. All ejection time corrected velocities $\left(\mathrm{S}_{(\mathrm{ET})}\right.$, mean $\left.\pm \mathrm{SEM}, \mathrm{cm} / \mathrm{s}\right)$ decreased significantly during hypoxia $\left(\mathrm{S}_{\mathrm{mva}(\mathrm{ET})} 15.5 \pm 0.2\right.$ to $13.2 \pm 0.3(p<0.001), \mathrm{S}_{\text {septal(ET) }} 9.9 \pm 0.1$ to $7.8 \pm 0.2$ $(p<0.001), \mathrm{S}_{\mathrm{tva}(\mathrm{ET})} 12.1 \pm 0.2$ to $\left.9.8 \pm 0.3(p<0.001)\right)$. The magnitude of change from baseline to hypoxia was greater for ejection time corrected systolic velocities than for RR-interval corrected velocities (mean $\pm \mathrm{SEM}, \mathrm{cm} / \mathrm{s}$ ); $\Delta \mathrm{S}_{\mathrm{mva}(\mathrm{ET})} 2.3 \pm 2.0$ vs. $\Delta \mathrm{S}_{\mathrm{mva}(\mathrm{RR})} 1.6 \pm 1.1(p=0.02)$,
\end{abstract}

H. H. Odland $(\bowtie) \cdot$ G. A. B. Kro · B. H. Munkeby ·

O. D. Saugstad

Department of Pediatric Research, Oslo University Hospital and University of Oslo, Oslo, Norway

e-mail: h.h.odland@medisin.uio.no

G. A. B. Kro

Department of Obstetrics and Gynecology,

Oslo University Hospital and University of Oslo, Oslo, Norway

T. Edvardsen

Institute for Surgical Research, Oslo University Hospital

and University of Oslo, Oslo, Norway

E. Thaulow

Department of Pediatric Cardiology, Oslo University Hospital, Rikshospitalet, 0027 Oslo, Norway
$\Delta \mathrm{S}_{\text {septal(ET) }} 2.1 \pm 1.0$ vs. $\Delta \mathrm{S}_{\text {septal(RR) }} 1.6 \pm 1.0(p<0.01)$ $\Delta \mathrm{S}_{\mathrm{tva}(\mathrm{ET})} 2.3 \pm 1.1$ vs. $\Delta \mathrm{S}_{\mathrm{tva}(\mathrm{RR})} 1.8 \pm 1.3(p=0.04)$. The receiver operator characteristic (ROC) showed superior performance of $\mathrm{S}_{(\mathrm{ET})}$ compared with uncorrected velocities. The decrease in $\mathrm{S}_{(\mathrm{ET})}$ during hypoxia was not influenced by important hemodynamic determinants. ET-corrected systolic velocity improves accuracy and decreases variability in the evaluation of systolic longitudinal function and contractility during global hypoxia in neonatal pigs compared with systolic velocity alone. It is robust toward hemodynamic changes. This novel method has the potential of becoming a useful tool in clinical practice.

Keywords Tissue Doppler - Myocardial function · Neonatal

\section{Introduction}

The systolic velocity of mitral valve annulus (MVA) displacement reflects the rate of volume reduction during systole $[4,5]$. Heart rate (HR) determines ejection time (ET) and hence the systolic ejection interval in which the displacement occurs. Ejection of a higher volume within a fixed interval necessitates a higher rate of volume reduction or MVA displacement after increased cardiac output (CO) at a higher HR. ET is stable relative to HR throughout childhood [6]. However, in the childhood population, body size is a stronger determinant of systolic velocity than HR, indicating the importance of heart size as a determinant factor for systolic velocity $[9,10,12,14,15,17,24,25]$. The changes in systolic velocity with growth are explained by differences in the allometric scaling of stroke volume and ET to body size [3, 7, 22]. An important feature of myocardial contractility is the ability of the cardiac myocardium to increase 
the velocity of contraction and thereby eject a higher volume at a shorter interval [28]. During hypoxia the opposite may occur [18]. The myocardial performance index is one example of an index that, among other parameters, incorporates the ET interval [26]. This indicates that both ET and stroke volume are important determinants of systolic velocity and that both change with contractility and allometrically to body size [22]. Knowing the relation toward each may allow for correction of the parameter to allow independent comparison. With tissue Doppler imaging techniques, both ET and systolic velocity may be assessed within a single heartbeat [1]. The aim of this study was to evaluate the effect of correcting systolic myocardial velocities for either ET or HR in an animal model. Neonatal pigs were chosen because of the relative similar size of the study subjects. We wanted to study whether the corrected parameters perform better than the uncorrected ones in describing changes in contractility that occur during hypoxia. We also wanted to look at how HR, systolic blood pressure (SBP), and left and right ventricular end diastolic diameter relate to peak systolic velocity and if the changes in hemodynamic parameters have any impact on tissue velocities.

\section{Materials and Methods}

\section{Animals}

Twenty-nine newborn Noroc pigs were included in the study Their weight was $1764 \pm 161$ (mean \pm SD) and inclusion criteria were age $12-36 \mathrm{~h}$, hemoglobin values $>5 \mathrm{~g} / \mathrm{dl}$, and good general condition. Anesthesia was induced by sevoflurane 5\% (Sevorane; Abbott); pentobarbital sodium $(20 \mathrm{mg} / \mathrm{kg})$ and fentanyl $(50 \mu \mathrm{g} / \mathrm{kg})$ were given intravenously as a bolus injection before instrumentation. Anesthesia was maintained by a continuous infusion of fentanyl $(50 \mu \mathrm{g} / \mathrm{kg} / \mathrm{h})$ and midazolam $(0.25 \mathrm{mg} /$ $\mathrm{kg} / \mathrm{h}$; IVAC P2000 infusion pump). When necessary, a bolus of fentanyl $(10 \mu \mathrm{g})$ or midazolam (1 mg) was added. The experimental protocol was approved by the hospital's Ethics Committee for Animal Studies under surveillance of the Norwegian Animal Experimental Board. The animals were cared for and handled in accordance with the European Guidelines for Use of Experimental Animals.

\section{Study Protocol}

Baseline was defined as the period $1 \mathrm{~h}$ after initial instrumentation and before introduction of hypoxia. The animals underwent hypoxia until base excess reached $-20 \mathrm{mmol} / \mathrm{l}$ or mean arterial BP decreased $<20 \mathrm{mmHg}$, as previously described by Munkeby et al. [16]. The animals were subsequently reoxygenated. Echocardiographic examination was performed at baseline, during hypoxia, and after reoxygenation. Velocities were assessed during ejection (S) in the septal and lateral parts of the MVA and in the lateral part of the TVA. A hemodynamic patent ductus arteriosus was excluded by echocardiography in all animals.

\section{Tissue Doppler Imaging}

Echocardiography was performed using a commercial available system (Vivid 7, GE Vingmed Ultrasound AS, Horten, Norway). A 10-MHz probe was chosen for imaging. All measurements are the average of three consecutive heartbeats. The temporal resolution was considered adequate with $>60$ frames/heartbeat. Spatial resolution was considered satisfactory when the annulus of interest in the apical four-chamber view was just within the image at end diastole. The depth and width were chosen to be as small as possible. The transducer was aligned parallel to the lateral wall and the septum to decrease angle failure by the Doppler technique. The Nyquist limit was set to $15 \mathrm{~cm} / \mathrm{s}$. Postprocessing was performed in the Q-analyzes mode with Echopac 6.0 software from GE without averaging of the curves. The region of interest (ROI) was chosen to be $4 \times 4 \mathrm{~mm}$ with a $0^{\circ}$ angle. It was placed just below the atrioventricular valve insertion in the annulus in the right lateral, the septal, or the left lateral position in the fourchamber view at the onset of the electrocardiogram (ECG). To track the tissue during the displacement of the annulus, the ROI was adjusted to fit with the MVA during isovolumic relaxation. The ROI was slightly repositioned to decrease artifacts if they occurred. ECG scans were obtained and stored together with the images. ET was extracted from the tissue velocity curve as the first deflection of the ejection curve to the first deflection of the isovolumic relaxation curve (Fig. 1) [1, 27]. Dimensions were measured in M-mode from the short-axis view.

\section{Hemodynamic Measurements}

An arterial end-hole single-lumen catheter was inserted through the femoral artery and advanced $8 \mathrm{~cm}$ into the artery for positioning in the descending aorta. Systolic and diastolic BP was measured with the Biopac MP150 acquisition system (Biopac Systems). Cardiac output was calculated based on two-dimensional echocardiographic images according to the biplane Simpsons method. Right and left ventricular enddiastolic and -systolic dimensions (right-ventricular enddiastolic diameter [RVEDD], left-ventricular end-diastolic diameter [LVEDD], and left-ventricular end-systolic diameter [LVESD], respectively) were calculated based on M-mode imaging in the parasternal long-axis projection. Systemic vascular resistance (SVR) was calculated from mean arterial BP divided by $\mathrm{CO}$. 


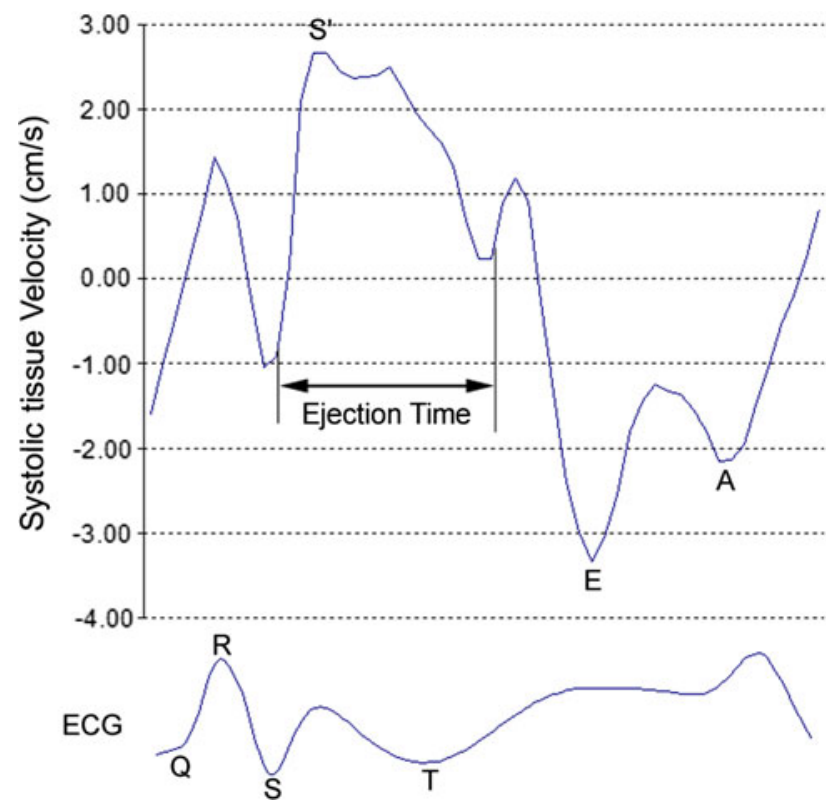

Fig. 1 Representative tissue velocity curve assessed in the lateral MVA. Corresponding ECG displayed below. $S$ ' systolic velocity; $E$ early diastolic velocity; $A$ late atrial velocity

\section{Correcting for ET and Cardiac Cycle Length Interval}

Correction for the impact of time interval on systolic myocardial velocities was performed with the beta coefficient from the slope of the mean linear regression line between the systolic tissue Doppler velocities (S) and time intervals (ejection time, ET) at baseline (Table 1). The new parameter (constant, $k$ ) was solved according to the formula for linear relation (Eq. 1):

$\mathrm{Y}=\mathrm{aX}+\mathrm{b}$,

$\mathrm{S}=\beta * \mathrm{ET}+k$,

$k=\mathrm{S}-\beta * \mathrm{ET}$

Which gives the following equation for the corrected parameter Eq. 2:

Corrected parameter $=$ systolic tissue velocity

$$
\text { - parameter estimate }(\beta)
$$$$
\text { * time interval. }
$$

Table 1 Correlations between ET/RR interval and the respective systolic velocity at baseline

\begin{tabular}{llllll}
\hline Velocities & \multicolumn{2}{l}{$\mathrm{RR}$ interval $(\mathrm{ms})$} & & $\mathrm{ET}(\mathrm{ms})$ & \\
\cline { 2 - 3 } & $\beta$ & $R^{2}$ & & $\beta$ & $R^{2}$ \\
\hline $\mathrm{S}_{\text {mva }}$ & -0.016 & $0.59^{* *}$ & & -0.061 & $0.64^{* *}$ \\
$\mathrm{~S}_{\text {septal }}$ & -0.006 & $0.258^{*}$ & & -0.038 & $0.57^{* *}$ \\
$\mathrm{~S}_{\text {tva }}$ & -0.006 & 0.18 & & -0.039 & $0.37^{*}$ \\
\hline
\end{tabular}

$\beta$ parameter estimate

$* p<0.05$

$* * p<0.001$
The parameter estimate $(\beta)$ is known from baseline regression analyses. $\beta$ indicates the magnitude and directional change in the tissue Doppler parameter for a 1 -unit increase in the time interval variable. The corrected parameter is constructed by subtracting the value accounted for by the change in time interval based on the known relation, $\beta$, between the two parameters. The corrected parameter represents the estimated value at the Y-intercept of the mean linear regression. We did not have any indications of a nonlinear relation in this study, although there might be a nonlinear relation over a wider range of cyclic intervals [22]. The corrected velocities, ET and cardiac cycle length, respectively, are noted with subscript (ET or cardiac cycle length (RR)), to indicate which time interval was used.

\section{Statistics}

The statistical package SPSS 14.0.0 for Windows were used for analyses. The $\beta$ coefficient describing the slope of the mean regression line, $\beta$, was calculated using linear regression. To differentiate the performance of the corrected from the uncorrected parameters in detecting hypoxic myocardium in this model, ROC were analysed. We included animals at baseline and during hypoxia and defined acquisitions performed during hypoxia as the state variable. ROC curves for paired samples were analyzed according to the methods of Hanley et al. and expressed as area under the curve (AUC) \pm SEM [11]. Linear mixed models with Bonferroni correction were used to assess the effects of change in experimental state (baseline, hypoxia, and reoxygenation) as well as the impact of hemodynamic determinants on the corrected and uncorrected tissue Doppler parameters in the pooled data set. For optimal model fit, unstructured covariance matrix was chosen as a covariance structure in the mixed model. Comparison of absolute decrease in velocity between uncorrected and corrected values was analyzed with two-tailed paired Student $t$ test. Unless otherwise stated, values are reported as means \pm SEMs. Significance was accepted when $p<0.05$. The investigators had full access to and take full responsibility for the integrity of the data.

\section{Results}

Correction of ET and RR Interval

Both the ET and RR interval was correlated with systolic velocities as listed in Table 1 . The effect of time interval correction on the systolic velocity parameters are listed in 
Table 2 The effect of correcting systolic tissue velocities by either ET or RR for all experimental stages

\begin{tabular}{|c|c|c|c|}
\hline Velocities & Baseline & Hypoxia & Postreoxygenation \\
\hline & \multicolumn{3}{|l|}{ Uncorrected values } \\
\hline $\mathrm{S}_{\mathrm{mva}}(n)$ & $5.73 \pm 0.37$ & $4.66 \pm 0.25 *(29)$ & $7.74 \pm 0.48 * *(26)$ \\
\hline $\mathrm{S}_{\text {septal }}(n)$ & $3.57 \pm 0.20$ & $2.28 \pm 0.21 * *$ & $3.90 \pm 0.30$ \\
\hline \multirow[t]{2}{*}{$\mathrm{S}_{\mathrm{tva}}(n)$} & $4.37 \pm 0.25(20)$ & $3.03 \pm 0.26^{* *}(20)$ & $4.84 \pm 0.35$ \\
\hline & \multicolumn{3}{|l|}{ ET-corrected values } \\
\hline $\mathrm{S}_{\mathrm{mva}}(n)$ & $15.5 \pm 0.22(28)$ & $13.3 \pm 0.31 * *$ & $15.7 \pm 0.32$ \\
\hline $\mathrm{S}_{\text {septal }}(n)$ & $9.90 \pm 0.13$ & $7.75 \pm 0.19 * *$ & $8.80 \pm 0.18 * *$ \\
\hline \multirow[t]{2}{*}{$\mathrm{S}_{\mathrm{tva}}(n)$} & $10.2 \pm 0.21$ & $7.90 \pm 0.25 * *$ & $9.38 \pm 0.33$ \\
\hline & \multicolumn{3}{|l|}{ RR-corrected values } \\
\hline $\mathrm{S}_{\mathrm{mva}}(n)$ & $12.3 \pm 0.24$ & $10.7 \pm 0.21 * *$ & $12.8 \pm 0.35$ \\
\hline $\mathrm{S}_{\text {septal }}(n)$ & $6.70 \pm 0.22(25)$ & $4.61 \pm 0.17 * *$ & $5.76 \pm 0.23$ \\
\hline $\mathrm{S}_{\mathrm{tva}}(n)$ & $6.20 \pm 0.18$ & $5.10 \pm 0.24 * *(22)$ & $6.54 \pm 0.29(22)$ \\
\hline
\end{tabular}

Values are estimated marginal means based on mixed models analyses (mean \pm SEM). Significance are displayed compared with baseline values with Bonferroni correction $(* p<0.05$ and $* * p<0.001)$

Table 2, which shows a general increase in the absolute numbers with a relative decrease in SE after correction, which was evident for all experimental stages. All ejection time corrected velocities $\left(S_{(E T)}\right.$, mean $\left.\pm S E M, c m / s\right)$ decreased significantly during hypoxia $\left(\mathrm{S}_{\mathrm{mva}(\mathrm{ET})} 15.5 \pm\right.$ 0.2 to $13.2 \pm 0.3(p<0.001), \mathrm{S}_{\text {septal(ET) }} 9.9 \pm 0.1$ to $7.8 \pm 0.2(p<0.001), \mathrm{S}_{\mathrm{tva}(\mathrm{ET})} 12.1 \pm 0.2$ to $9.8 \pm 0.3$ $(p<0.001))$. The magnitude of change from baseline to hypoxia was greater for ejection time corrected systolic velocities than for RR-interval corrected velocities (mean $\pm \mathrm{SEM}, \mathrm{cm} / \mathrm{s}) ; \Delta \mathrm{S}_{\mathrm{mva}(\mathrm{ET})} 2.3 \pm 2.0$ vs. $\Delta \mathrm{S}_{\mathrm{mva}(\mathrm{RR})}$ $1.6 \pm 1.1(p=0.02), \Delta \mathrm{S}_{\text {septal(ET) }} 2.1 \pm 1.0$ vs. $\Delta \mathrm{S}_{\text {septal(RR) }}$ $1.6 \pm 1.0(p<0.01), \Delta \mathrm{S}_{\mathrm{tva}(\mathrm{ET})} 2.3 \pm 1.1$ vs. $\Delta \mathrm{S}_{\mathrm{tva}(\mathrm{RR})}$ $1.8 \pm 1.3(p=0.04)$ (Fig. 2). A good correlation was found between ET and RR (Fig. 3), indicating a stable relation between the two.

\section{ROC Curve Analyses}

ET-corrected parameters were significantly better in differentiating hypoxic state from baseline: $\mathrm{S}_{\mathrm{mva}(\mathrm{ET})} \mathrm{AUC}=$ $0.87 \pm 0.07$ vs. $S_{\text {mva }}$ AUC $=0.66 \pm 0.05 \quad(p<0.001)$; $\mathrm{S}_{\text {septal(ET) }} \mathrm{AUC}=0.95 \pm .03$ vs. $\mathrm{S}_{\text {septal }} \mathrm{AUC}=0.83 \pm$ $0.06(p=0.01)$; and $\mathrm{S}_{\mathrm{tva}(\mathrm{ET})} \mathrm{AUC}=0.95 \pm 0.03$ vs. $\mathrm{S}_{\mathrm{tva}} \mathrm{AUC}=0.73 \pm 0.03(p<0.001)$. The AUC between the corrected parameters were only different for $\mathrm{S}_{\mathrm{tva}(\mathrm{ET})}$ $\mathrm{AUC}=0.95 \pm 0.03 \quad$ vs. $\quad \mathrm{S}_{\mathrm{tva}(\mathrm{RR})} \mathrm{AUC}=0.86 \pm 0.06$ $(p=0.01)$.
Fig. 2 Reduction in absolute numbers from baseline to hypoxia, for uncorrected and corrected parameters.

$* p<0.05$ Comparison of the uncorrected baseline parameter with the ET and RR corrected parameter. ${ }^{\#} p<0.05$ Comparison of the corrected baseline parameter with the ET and RR corrected parameter

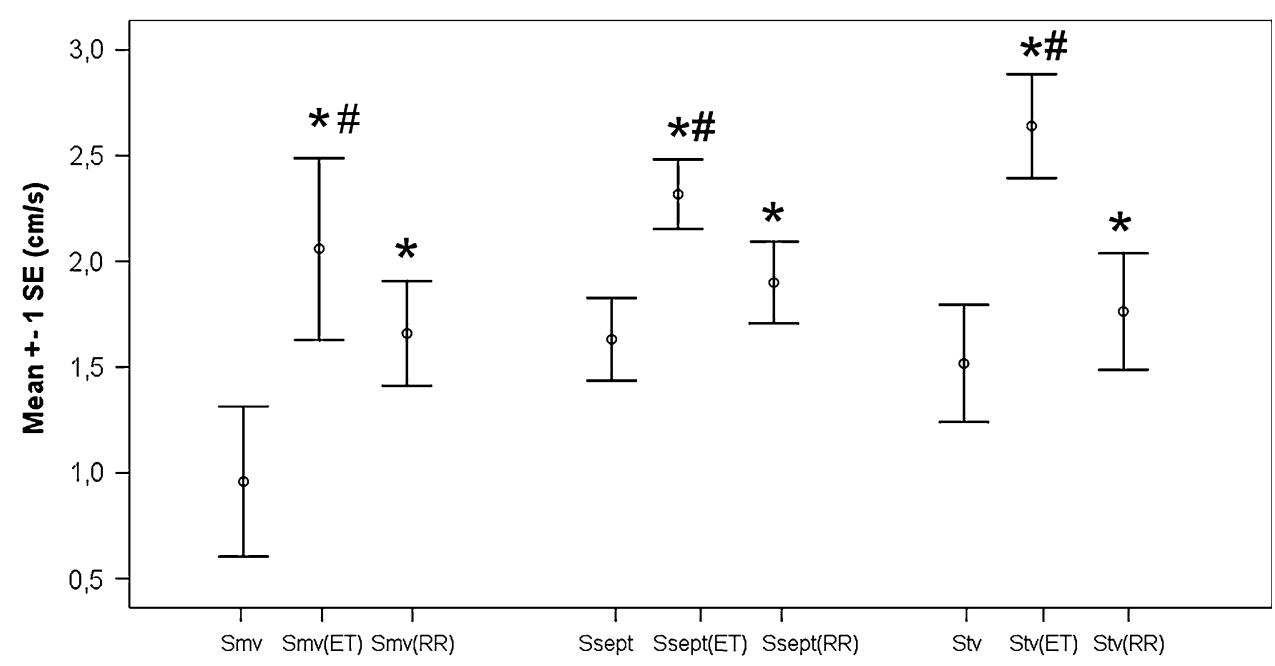




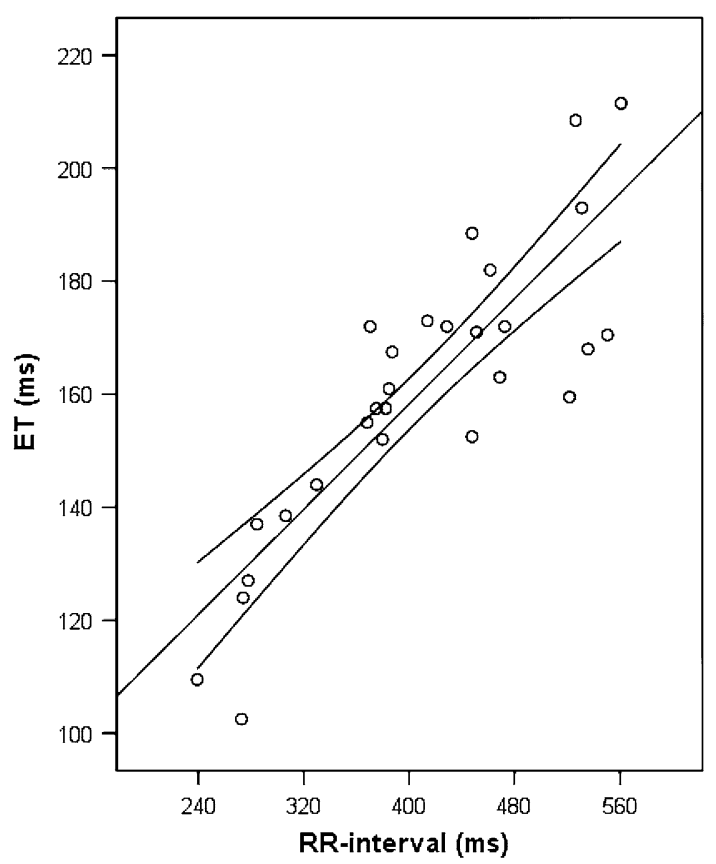

Fig. 3 Correlation between RR (ms) and ET (ms) at baseline and confidence interval of the mean $\left(R^{2}=0.72, \beta=233, p<0.001\right)$

Time Intervals

Linear regression between time intervals and velocities showed a strong correlation for MVA. The same correlation was apparent but weaker for the septum and the TVA (Fig. 4a). The correlation between ET and systolic velocity was better with septal velocities than the correlation with the RR interval. Both $S_{\mathrm{mva}}$ and $\mathrm{S}_{\text {septal }}$ were better correlated with ET than $\mathrm{S}_{\mathrm{tva}}$, both at baseline and after reoxygenation. We did not find any correlation between ET and LVEDD at any stage during the study. At baseline, ET and SBP were correlated $\left(R^{2}=0.36, \beta=-0.37, p=0.002\right)$. During hypoxia there was a correlation between ET and RVEDD $\left(R^{2}=0.27, \beta=0.05, p=0.01\right)$, and after reoxygenation ET correlated with $\operatorname{SBP}\left(R^{2}=0.21, \beta=-0.31, p=0.03\right)$ and $\operatorname{RVEDD}\left(R^{2}=0.18, \beta=0.03, p=0.05\right)$.

Hemodynamic and Biochemical Parameters

The most prominent change in hemodynamic parameters from baseline to hypoxia was the change in systolic BP, which decreased $>50 \%$ (Table 3). ET and LVEDD decreased to lower values, whereas RVEDD increased during hypoxia. LVESD and CO did not change. There were significant changes in systemic vascular resistance from baseline to both hypoxia and after reoxygenation. Postischemic responses consisted of increased HR, which was reflected in decreased HR and ET compared with baseline values. SBP did not reach baseline values after reoxygenation. Lactate and $\mathrm{pH}$ changed as expected in the experimental model.

Age and Weight

There were significant $(p<0.05)$ correlations between $\mathrm{S}_{\mathrm{mva}}, \mathrm{S}_{\text {septal }}$, and postnatal age and between $\mathrm{S}_{\mathrm{mva}}$ and weight. However, the only corrected parameter associated with age or weight was $\mathrm{S}_{\mathrm{mva}(\mathrm{RR})}$ (vs. weight $R^{2}=0.2$, $p=0.03)$.

Multivariate Linear Mixed-Models Analysis

Table 4 lists results of the systolic velocities when SBP, $\mathrm{HR}$, and LVEDD/RVEDD were included as hemodynamic determinants in multvariate linear mixed-model analyses (respectively, on $\mathrm{S}_{\mathrm{mva}} / \mathrm{S}_{\text {septal }}$ and $\mathrm{S}_{\mathrm{tva}}$ ). The impact of hypoxia on ET-corrected systolic velocities was still significant after correcting for the hemodynamic determinants (Table 4). For $\mathrm{S}_{\text {septal(ET) }}$ and $\mathrm{S}_{\mathrm{tva(ET)}}$, the impact of hypoxia consisted of a significant change from baseline to hypoxia and from hypoxia to postreoxygenation, whereas $S_{\mathrm{mva}(\mathrm{ET})}$ changed significantly from hypoxia to postreoxygenation (Table 4). RVEDD was used in the model of velocities in the TVA.

\section{Discussion}

This study shows that much variability is eliminated, and accuracy gained, by correcting systolic velocity for impact of the ET. ET-corrected systolic velocities are less influenced by hemodynamic parameters. The effect of correcting for ET is an overall increase of the absolute value because of the negative correlation to systolic velocities; hence, there is a higher Y-intercept of the mean regression line (Eq. 2). Additional effects include decreased SD. This is reflected in higher sensitivity and specificity in the ROC curve analyses. The increase in accuracy with correction may be explained by elimination of the influence of ET on the tissue velocities. The difference between cycle length (RR) correction and ET correction may be explained by the closer causal relation between ET and systolic velocities and the more parallel phenomenon of a decrease in RR with ET (Fig. 3). The RR interval incorporates diastolic events as well. We did not find any correlations between ET and LVEDD or RVEDD, which enhances the point of including ET in the model as an independent determinant of systolic velocities. The decrease in corrected tissue velocities during hypoxia represents a decrease in velocity relative to the time period in which a certain velocity would be expected. Any change in the relation between ET and systolic velocity may therefore be considered as a 

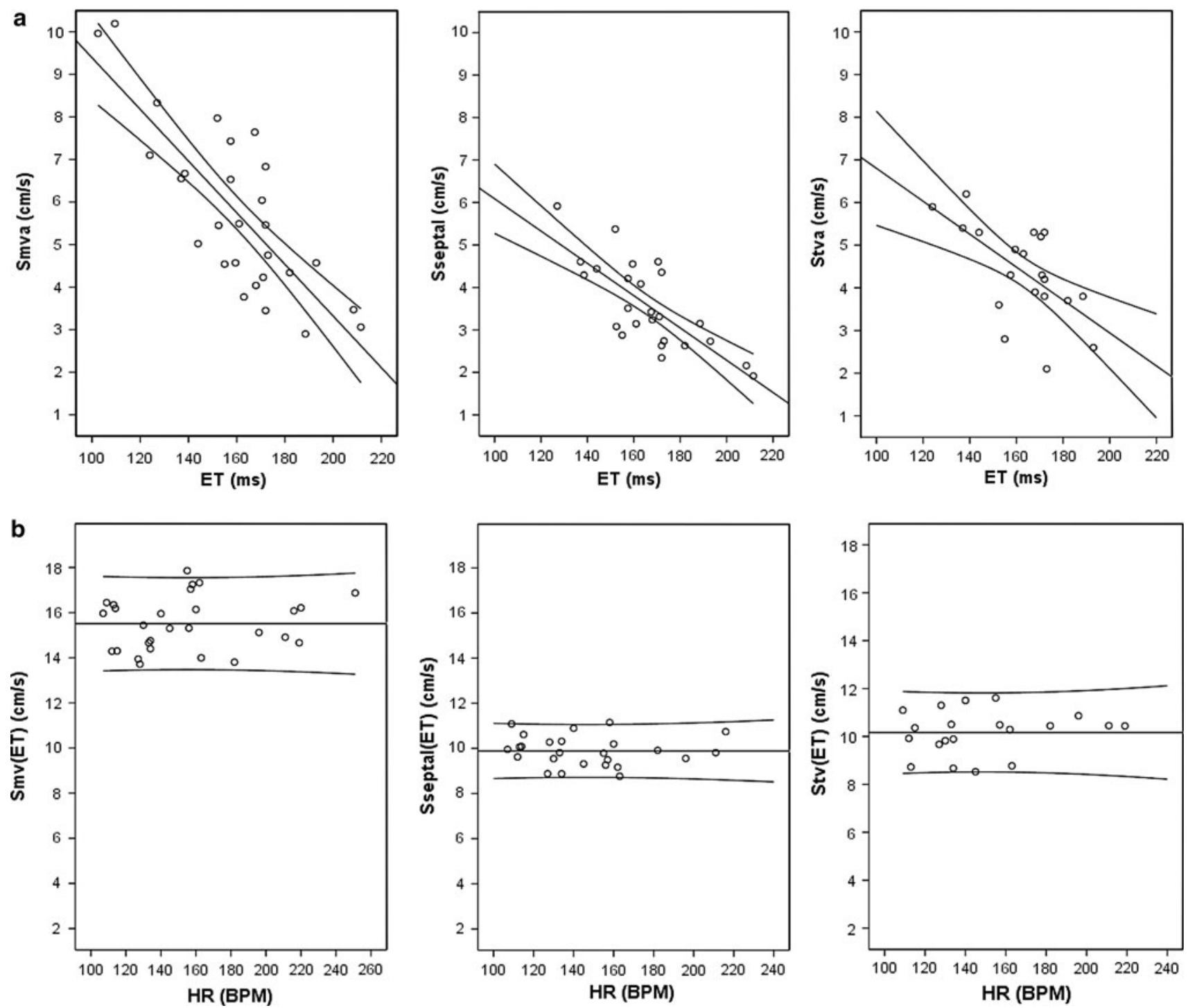

Fig. 4 The effect of correcting tissue velocities based on the Y-intercept of the mean linear regression line between ET and systolic velocities at baseline. a Regression lines (with confidence intervals of the mean) showing the relationship between systolic velocity at three different sites in the heart and ejection time. b Scatter diagrams (with confidence intervals of the mean) showing the corrected systolic velocities plotted against heart rate

evaluating systolic velocities impractical for clinical use [24]. The dispersion seen in these materials could be the result of differences in resting hemodynamics and size heterogeneity within in each age group. It is difficult to determine which is more important. In some studies, age and body size were stronger predictors of systolic velocity than HR, whereas others have reported stronger effects of HR $[9,14,21]$. The influence of body size described by other investigators could not be reproduced in this study [9]. Our data are characterized by a relative homogeneity toward weight and a relative heterogeneity toward HR and ET. In this way, changes in systolic velocity in this study is more related to HR than to size of the heart. The relation at baseline between HR, ET, and systolic velocity was not
Published z-scores from normal materials in children are hampered with dispersion, which makes the method of 
Table 3 Hemodynamic and biochemical measurements

\begin{tabular}{lccc}
\hline $\begin{array}{l}\text { Hemodynamic/ } \\
\text { biochemical } \\
\text { parameter }\end{array}$ & Baseline & Hypoxia & Postreoxygenation \\
\hline HR (bpm) & $155 \pm 8$ & $164 \pm 5$ & $195 \pm 7^{* *}$ \\
RR (ms) & $409 \pm 18$ & $376 \pm 12$ & $319 \pm 13^{* *}$ \\
ET (ms) & $160 \pm 5$ & $141 \pm 5^{*}$ & $131 \pm 4^{* *}$ \\
SBP (mmHg) & $75 \pm 3$ & $36 \pm 2^{* *}$ & $56 \pm 3^{* *}$ \\
CO (ml/min) & $187 \pm 14$ & $150 \pm 8$ & $210 \pm 13$ \\
SVR (mmHg*1/ & $358 \pm 30$ & $182 \pm 12^{* *}$ & $224 \pm 13^{* *}$ \\
$\quad$ min) & & & \\
LVEDD (mm) & $15.4 \pm 0.4$ & $13.8 \pm 0.4^{*}$ & $14.7 \pm 0.5$ \\
LVESD (mm) & $10.4 \pm 0.4$ & $9.4 \pm 0.4$ & $10.1 \pm 0.4$ \\
RVEDD (mm) & $7.0 \pm 0.3$ & $9.0 \pm 0.4^{* *}$ & $7.3 \pm 0.3$ \\
pH & $7.45 \pm 0.14$ & $6.96 \pm 0.10^{* *}$ & $7.32 \pm 0.09^{* *}$ \\
Lactate (mmol/l) & $3.2 \pm 2.3$ & $11.6 \pm 4.2^{* *}$ & $7.9 \pm 3.6^{* *}$ \\
\hline
\end{tabular}

$H R$ heart rate, $R R$ cardiac cycle length, $E T$ ejection time, $C O$ cardiac output, $S V R$ systemic vascular resistance, $L V E D D$ left ventricular end-diastolic diameter, SBP systolic BP, LVESD left-ventricular endsystolic diameter, $R V E D D$ right ventricular end-diastolic diameter

Values are means \pm SEMs. Significance are displayed compared with baseline values with Bonferroni correction $(* p<0.05$ and $* * p<0.001)$

Table 4 Calculated mean values for respective velocity when corrected for hemodynamic determinants (SBP, HR, and LVEDD/ RVEDD)

\begin{tabular}{lrcc}
\hline Velocities & \multicolumn{1}{c}{ Baseline } & \multicolumn{1}{c}{ Hypoxia } & Postreoxygenation \\
\hline $\mathrm{S}_{\text {mva }}$ & $5.6 \pm 0.4$ & $5.2 \pm 0.3$ & $7.0 \pm 0.3^{*}$ \\
$\mathrm{~S}_{\text {mva(RR) }}$ & $11.6 \pm 0.4$ & $11.0 \pm 0.3$ & $12.9 \pm 0.3^{*}$ \\
$\mathrm{~S}_{\mathrm{mva}(\mathrm{ET})}$ & $15.3 \pm 0.5$ & $13.4 \pm 0.4^{*}$ & $15.6 \pm 0.3^{*}$ \\
$\mathrm{~S}_{\text {septal(ET) }}$ & $9.3 \pm 0.3$ & $7.9 \pm 0.2^{* *}$ & $8.7 \pm 0.2^{\dagger}$ \\
$\mathrm{S}_{\mathrm{tva}(\mathrm{ET})}$ & $9.8 \pm 0.4$ & $8.1 \pm 0.3^{*}$ & $9.3 \pm 0.4$ \\
\hline
\end{tabular}

The table shows the estimated marginal means of the tissue velocities on which hypoxia had a significant impact after correcting for the hemodynamic determinants in the multivariate linear mixed-model analyses. For all other tissue velocities, the multivariate correction accounted for all significant changes that were seen in the velocity parameters without correction

Values are mean $\pm \mathrm{SEM} * p<0.05$ compared with baseline; $* * p<0.01$ compared with baseline; ${ }^{\dagger} p<0.05$ compared with hypoxia; ${ }^{*} p<0.01$ compared with hypoxia. Post hoc analyses with Bonferroni correction were performed

influenced by heart size as determined by statistical analyses. ET-corrected parameters seem robust toward the small changes in age and weight seen in this study.

The results of our study, however, support the concept of allometric scaling. Changes related to body size may be explained by different allometric scaling of ET and stroke volume $[3,7,22]$. Differences in individuals with similar heart size may be explained by differences in HR. The article from Quintana et al. showed how velocity increases with HR and how this effect is attenuated by $\beta$ blockade [23]. They showed a clear effect of less increase in systolic velocity relative to ET as a response to $\beta$ blockade.

\section{Multivariate Linear Mixed-Model Analysis}

By accounting for the changes caused by HR and surrogate markers of preload (LVEDD/RVEDD) and afterload (SBP) in the multivariate linear mixed-model analyses, velocity changes caused by a change in state (baseline, hypoxia, postreoxygenation) were dissected. The hemodynamic variables accounted for all of the changes seen in uncorrected systolic velocities. For the ET-corrected parameters, the influence of hypoxia was still significant after correcting for hemodynamic determinants. Hypoxia did influence either the change from baseline to hypoxia or from hypoxia to postreoxygenation (Table 3). This underlines the independent ability of ET-corrected velocity to reflect myocardial longitudinal function. SBP was the only parameter that significantly explained changes in ET-corrected velocities, interestingly only in the septum, which is in concordance with previously published results [20].

\section{Hemodynamics}

In this model, RVEDD increased; LVEDD decreased together with SBP and SVR during hypoxia; and CO did not change. This indicates that the expected pulmonary hypertension and right-ventricular dysfunction during hypoxia is followed by decreased right-ventricular output with increased right-ventricular end-diastolic pressure. This increase in preload on the right side is opposite to the hemodynamics on the left side, i.e., decreased preload and subsequently low $\mathrm{CO}$ from the left ventricle with inadequate filling of the systemic circulation and decreased vascular resistance with low systolic BP as a result. This serial phenomenon of a failing right ventricle that alters preload of the left ventricle is of great importance in the neonate. Ventricular interaction during pulmonary hypertension may also play a role in this [2]. In this study, left-ventricular dilatation was not seen during hypoxia. However, the right-ventricular dimension did increase. Increased pulmonary vascular resistance, pericardial constraint, and decreased compliance of the right ventricle may all contribute to decreased pulmonary blood flow, resulting in decreased preload on the left side. The neonatal myocardium is fairly non-compliant; working on high enddiastolic volumes. On the contrary, piglet hearts have been shown to have relatively similar compliance as adult swine [13]; however, new data suggest that regulation of titin isoforms may play an important role in myocardial stiffening in the piglet heart as well [19]. Interestingly, the responses of the myocardium to oxygen deprivation do not 
include decreased compliance of the heart; moreover, myocardial function decreases according to oxygen deprivation to preserve myocardial viability, which is in keeping with our data [8]. This demonstrates the unique nature of neonatal physiology; however, it does not undermine the importance of accurate measurements of ventricular function in this age group. The differences between the tricuspid annulus, the septum, and the MVA seen in this study may in part be explained by the differences in preload, afterload, compliance of the respective ventricles, and ventricular interaction.

\section{Limitations}

This study was limited by examining neonates in the first days of life, and extrapolation of the effects of correcting for ET to larger body sizes may not be appropriate.

\section{Conclusion}

ET-corrected systolic velocity decreased the variability and improved the accuracy of systolic tissue Doppler velocities for the evaluation of systolic longitudinal function and contractility during global hypoxia in newborn piglets. It was not influenced by hemodynamic parameters, age, and weight. The measurement had validity for both left lateral, septal, and right ventricular longitudinal function. The validity of relating systolic velocity to the ET as a measure of contractility should be further assessed before expanding these results to larger-sized individuals. ET-corrected systolic velocity is a fast and reliable method of addressing myocardial mechanics with the potential to improve clinical assessment of myocardial function.

Acknowledgment This work was supported by the Norwegian Council on Cardiovascular Disease, Norwegian Health Association.

Open Access This article is distributed under the terms of the Creative Commons Attribution Noncommercial License which permits any noncommercial use, distribution, and reproduction in any medium, provided the original author(s) and source are credited.

\section{References}

1. Aase SA, Torp H, Stoylen A (2008) Aortic valve closure: relation to tissue velocities by Doppler and speckle tracking in normal subjects. Eur J Echocardiogr 9:555-559

2. Ama R, Leather HA, Segers P, Vandermeersch E, Wouters PF (2006) Acute pulmonary hypertension causes depression of left ventricular contractility and relaxation. Eur J Anaesthesiol 23:824-831

3. Batterham A, Shave R, Oxborough D, Whyte G, George K (2008) Longitudinal plane colour tissue-Doppler myocardial velocities and their association with left ventricular length, volume, and mass in humans. Eur J Echocardiogr 9:542-546

4. Carlsson M, Ugander M, Heiberg E, Arheden H (2007) The quantitative relationship between longitudinal and radial function in left, right, and total heart pumping in humans. Am J Physiol Heart Circ Physiol 293:H636-H644

5. Carlsson M, Ugander M, Mosen H, Buhre T, Arheden H (2007) Atrioventricular plane displacement is the major contributor to left ventricular pumping in healthy adults, athletes, and patients with dilated cardiomyopathy. Am J Physiol Heart Circ Physiol 292:H1452-H1459

6. Cui W, Roberson DA, Chen Z, Madronero LF, Cuneo BF (2008) Systolic and diastolic time intervals measured from Doppler tissue imaging: Normal values and $\mathrm{z}$-score tables, and effects of age, heart rate, and body surface area. J Am Soc Echocardiogr $21: 361-370$

7. de Simone G, Devereux RB, Daniels SR, Mureddu G, Roman MJ, Kimball TR et al (1997) Stroke volume and cardiac output in normotensive children and adults: assessment of relations with body size and impact of overweight. Circulation 95:1837-1843

8. Downing SE, Chen V (1990) Myocardial hibernation in the ischemic neonatal heart. Circ Res 66:763-772

9. Eidem BW, McMahon CJ, Cohen RR, Wu J, Finkelshteyn I, Kovalchin JP et al (2004) Impact of cardiac growth on Doppler tissue imaging velocities: a study in healthy children. J Am Soc Echocardiogr 17:212-221

10. Ekici F, Atalay S, Ozcelik N, Ucar T, Yilmaz E, Tutar E (2007) Myocardial tissue velocities in neonates. Echocardiography 24:61-67

11. Hanley JA, McNeil BJ (1983) A method of comparing the areas under receiver operating characteristic curves derived from the same cases. Radiology 148:839-843

12. Hiarada K, Orino T, Yasuoka K, Tamura M, Takada G (2000) Tissue Doppler imaging of left and right ventricles in normal children. Tohoku J Exp Med 191:21-29

13. Lee JC, Downing SE (1974) Left ventricular distensibility in newborn piglets, adult swine, young kittens, and adult cats. Am J Physiol 226:1484-1489

14. Mori K, Hayabuchi Y, Kuroda Y, Nii M, Manabe T (2000) Left ventricular wall motion velocities in healthy children measured by pulsed wave Doppler tissue echocardiography: normal values and relation to age and heart rate. $\mathrm{J}$ Am Soc Echocardiogr 13:1002-1011

15. Mori K, Nakagawa R, Nii M, Edagawa T, Takehara Y, Inoue M et al (2004) Pulsed wave Doppler tissue echocardiography assessment of the long axis function of the right and left ventricles during the early neonatal period. Heart 90:175-180

16. Munkeby BH, Borke WB, Bjornland K, Sikkeland LI, Borge GI, Halvorsen B et al (2004) Resuscitation with $100 \%$ O2 increases cerebral injury in hypoxemic piglets. Pediatr Res 56:783-790

17. Nilsson B, Bojo L, Wandt B (2002) Influence of body size and age on maximal diastolic velocity of mitral annulus motion. J Am Soc Echocardiogr 15:29-35

18. Odland HH, Kro GA, Edvardsen T, Thaulow E, Saugstad OD (2009) Atrioventricular valve annulus velocity and acceleration during global hypoxia in newborn pigs-assessment of myocardial function. Neonatology 97:100-107

19. Opitz CA, Leake MC, Makarenko I, Benes V, Linke WA (2004) Developmentally regulated switching of titin size alters myofibrillar stiffness in the perinatal heart. Circ Res 94:967-975

20. Park HS, Naik SD, Aronow WS, Visintainer PF, Das M, McClung JA et al (2006) Differences of lateral and septal mitral annulus velocity by tissue Doppler imaging in the evaluation of left ventricular diastolic function. Am J Cardiol 98:970-972

21. Pasquet A, Armstrong G, Rimmerman C, Marwick TH (2000) Correlation of myocardial Doppler velocity response to exercise 
with independent evidence of myocardial ischemia by dual-isotope single-photon emission computed tomography. Am J Cardiol 85:536-542

22. Popovic ZB, Sun JP, Yamada H, Drinko J, Mauer K, Greenberg NL et al (2005) Differences in left ventricular long-axis function from mice to humans follow allometric scaling to ventricular size. J Physiol 568:255-265

23. Quintana M, Gustafsson T, Sundblad P, Langanger J (2005) The effects of heart rate on myocardial velocity and atrio-ventricular displacement during exercise with and without beta-blockade: a tissue Doppler echocardiographic study. Eur J Echocardiogr 6:127-133

24. Roberson DA, Cui W, Chen Z, Madronero LF, Cuneo BF (2007) Annular and septal Doppler tissue imaging in children: Normal z-score tables and effects of age, heart rate, and body surface area. J Am Soc Echocardiogr 20:1276-1284
25. Swaminathan S, Ferrer PL, Wolff GS, Gomez-Marin O, Rusconi PG (2003) Usefulness of tissue Doppler echocardiography for evaluating ventricular function in children without heart disease. Am J Cardiol 91:570-574

26. Tei C, Nishimura RA, Seward JB, Tajik AJ (1997) Noninvasive Doppler-derived myocardial performance index: correlation with simultaneous measurements of cardiac catheterization measurements. J Am Soc Echocardiogr 10:169-178

27. Weidemann F, Eyskens B, Sutherland GR (2002) New ultrasound methods to quantify regional myocardial function in children with heart disease. Pediatr Cardiol 23:292-306

28. Zhong L, Tan RS, Ghista DN, Ng EY-K, Chua LP, Kassab GS (2007) Validation of a novel noninvasive cardiac index of left ventricular contractility in patients. Am J Physiol Heart Circ Physiol 292:H2764-H2772 